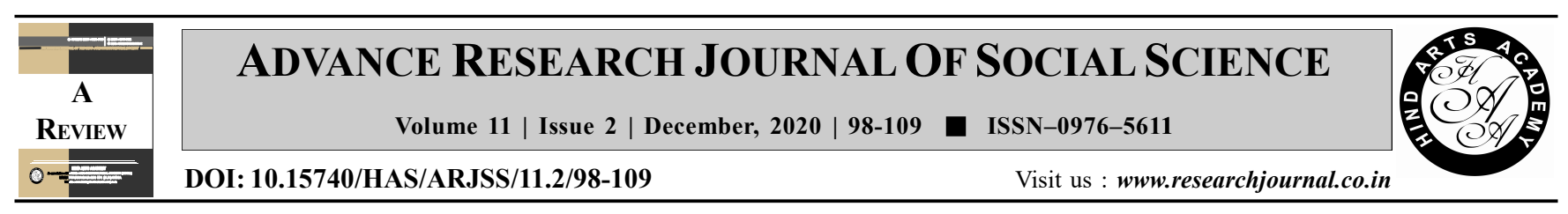

\title{
Elderly patients and the role of nurses and caregivers in home health care - An anthropological perspective
}

Ramandeep Bawa* and A. K. Sinha Centre for Advanced Studies in Anthropology, Panjab University, Chandigarh, India (Email : sodhiramandeep9@gmail.com; ksinha_anil@pu.ac.in)

\section{ARTICLE INFO :}

Received : 19.09 .2020

Accepted : 11.11 .2020

*Author for correspondence
KEY WORDS :

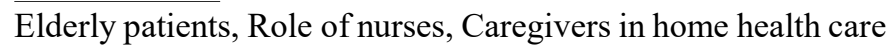

HOW TO CITE THIS ARTICLE :

Bawa, Ramandeep and Sinha, A.K. (2020). Elderly patients and the role of nurses and caregivers in home health care - An anthropological perspective. Adv. Res. J. Soc. Sci., 11 (2): 98-109, DOI: 10.15740/HAS/ARJSS/11.2/98-109.Copyright@2020:Hind Agri- Horticultural Society 